\title{
Signal and Video Processing: Developing the Noise Music Trend in Digital Edugaming
}

\author{
Ieva Gintere, \\ Institute of Social, Economic and Humanities Research, \\ Vidzeme University of Applied Sciences, \\ Cēsu iela 4, Valmiera, LV 4201 \\ Latvia
}

\begin{abstract}
In digital educational gaming, there are presently no games devoted to the trends of contemporary music. Also, there are no studies of noise-related sound in contemporary gaming discourse, yet noise is presently one of the most current trends in the arthouse world. The author of this study is carrying out a post-doctoral research into contemporary audio-visual art and digital game theory. Next to the other trends of modern gaming, the study incorporates analysis of noise-related artefacts that are of particular interest to the author taking into account her musicological education. The author intends to transfer knowledge gathered in the research process to the general public with an aim to facilitate the comprehension of noise music. Noise-related sound does not belong to the traditional system of musical expression thereof it requires an explanation and justification in order to be well apprehended. It has been explained in the literature of musicology, but serious gaming would help to disseminate these results and thus support intellectual education. The new experimental game Art Space explores the noise effect in order to deepen the understanding of this fuzzy area of contemporary culture. The game incorporates the historical background of noise music and its contemporary examples in the academic and alternative genres. The methods used in this study are literature analysis (theory of gaming and musicology), analyses of game sound scores and music examples. The mission of the research project and the innovative game Art Space is to pave the way to a new type of edugame that supports the documentation and analysis of aesthetical trends today.
\end{abstract}

Keywords - Contemporary music, educational game, art game, noise.

\section{INTRODUCTION}

$I^{N}$ $\mathrm{N}$ contemporary art gaming and educational (also called serious) gaming, there are almost no games at present that would teach and explain the trends of contemporary art and its historical context. A couple of games are related to contemporary art and serious gaming, although they do not explain the conceptual framework and historical roots of the new audio-visual art.

Art today is not an easy area for the general public taking into account its highly intellectual nature, unusual styles and many references to other works of art as well as theoretical sources formed as an intertextual network. Inherited largely from the era of modernism, contemporary art incorporates a knowledge cache or coded messages that generally demand a specific education in order to be fully grasped. Although the tradition of aesthetics that governs the audio-visual expression nowadays is already around a hundred years old, it still needs additional explanations in many cases. Being an interactive media and one of the dominant cultural forms over the past couple of decades, digital gaming is a suitable way to ease the understanding and appreciation of contemporary art. The author of this study outlines a prototype of an experimental educational game, Art Space, devoted to the recent trends of gaming aesthetics. Art Space is being created in the time period between 2019 and 2021 in the framework of a postdoctoral study.

The aim of the project is to document and analyze contemporary gaming aesthetics, and to create a new type of serious games that explains the multi-faceted aspects of audiovisual styles. The target audience of the game are mainly students of universities and colleges related to culture as well as hopefully other fields. The author has previously analyzed trends of contemporary gaming and their embodiment in Art Space [1]. This article is focused on noise-related sound that is one of the most current trends in the field of music today. The author is particularly interested in noise music. Her $\mathrm{PhD}$ thesis in musicology was dedicated to the newest trends in academic music. In the thesis, the author has already outlined the feature of sound-cloud or blocks of sound characteristic to noise music [2].

This article poses the questions of how game artists and creative practitioners can reflect upon the cultural values embedded in games by creating a new type of game, and how it can be used to bring about social change, namely, the acceptance of the artistic practice of the current century. Referencing Mary Flanagan [3], the author is working on a game that "can be said to foster a critical thinking type of game". 
The article highlights the history of noise-related sound and describes its manifestations in academic and alternative music, as well as sketches the results of analysis in the literature of musicology and gaming. It has been acknowledged that noise is a prominent tendency that nevertheless requires a theoretical assistance for listeners because of its still obscure identity and ambiguity in the modern system of cultural values.

Noise tendency has been well explained in musicology, however, it needs to be developed for two reasons. Firstly, the examples of noise artefacts in gaming are underrepresented. As a result, there is no comprehensive documentation and analysis of noise-related sound that has been developed recently. Secondly, the existing results of musicological analysis in the field of noise have not been used in serious gaming to date. The project of Art Space is created to open up a new page in gaming devoted to disseminate the results of recent research about the concept of noise and other current trends in musicology and theory of culture. Art Space will function as a prototype for innovative games in future with an aim to demonstrate newest issues of contemporary artistic activity and support intellectual education.

\section{Mission OF THE New GAME AND its Contribution to EDUGAMING}

\section{A. General Concept of Art Space}

Art Space is a virtual multi-storey art academy where a player can interact creatively and learn. The player takes an elevator and moves upwards and downwards through levels named after the trends of contemporary art such as glitch, hacking, futurism, pixel art, kitsch/camp, naïve art, photorealism, and generative art. One of its levels presents the noise music room that is the main subject of this article.

In this project, the concept of noise covers the field of glitch, failure aesthetics and other types of contemporary auditory phenomena in the widest context of modern sound that has no classical limits of pitch, rhythm and timbre. The concept of noise incorporates alternative, underground and also academic music where the classical terms of a solid sound have been essentially changed in favor of sound clouds, atonal acoustic figures and unconventional playing techniques [2]. This sound-world can be called noise-related since it might not be always directly noisy yet it is based on the concept of sound founded by Luigi Russolo and John Cage. This concept, developed around the second half of the $20^{\text {th }}$ century, predicates that sounds in art are tumultuous and uncanny in terms of conventional understanding of music.

The concept of noise-related sound may be confusing to the public without a particular education in contemporary theory of culture. In the futurism manifesto (1913), Russolo denoted that music has become shrilly, strange, random, and dissonant [4]. Through the avant-garde piece 4'33" (1952), Cage suggested that any sound can be a part of an acoustic piece. In future, he wrote, music will be the "entire field of sound" [5]. Likewise, Luciano Berio declared that music can be everything that one listens to with the intention of listening to music [6]. These authors have obscured the line between music and disturbance and rendered any music/otherness binary irrelevant. The noise-related sound is an innovative artistic expression of the modern mind that operates not with the harmonic images of a pure sound characteristic to the classical and romantic era, but with fresh means of expression opening a new horizon of the acoustic experience and broadening the framework of musicality. It is not a musical aberration or an opposition to music, but an experimental adventure that helps to write the new history of sound.

In the noise room, Art Space briefly explains the purposes and reasons for the noise music tradition. It provides a learning experience and the opportunity to make the contemporary sound field more familiar to the audiences also outside of the universities and colleges of culture. Next to the acoustic experience, the game offers an information text in a threedimensional space that tells about the theoretical aspects of contemporary gaming aesthetics and describes its historical background.

\section{B. Situation of Edugaming Considering Contemporary Art} and Music

In her article, Elizabeth Hunter speaks about the complex language of Shakespeare's that functions as "a barrier" to its audience. She suggests creating a digital game that would help readers decode the specific Shakespearean language and thus better understand and enjoy his plays [7]. Much like the Hunter's game, Art Space aims at familiarizing the noise music tradition so that people feel more intrinsically motivated to accept it. Even though art, as suggested by Umberto Eco [8] and Roland Barthes [9], is an open text that can be read freely by anyone regardless of his/her experience, the knowledge of cultural backgrounds can lead to a deeper understanding.

As the aesthetics of digital art games is strongly affected by the aesthetics of modernism, the analysis of its historical aspect is one of the crucial things needed to carry out a meaningful analysis. Game researchers have named several aspects of the game analysis, however, the historical aspect of the games related to contemporary art and music has not been thoroughly described. Even though the situation of the historical heritage in digital gaming has been sufficiently analyzed [10]-[12], the subfield of contemporary art and music has been neglected to date. The same can be said about some recent literature reviews concerning serious gaming in the context of culture [13], [14]. The goal of this study is to show the reliance of historical artefacts and concepts of art theory to contemporary gaming, focusing on the niche of noise-related sound.

\section{A Short Analysis of the Noise-related Scores}

In the existing literature, there is a sufficient analysis of historical context of noise, however, the newest sound scores of games have not been analyzed yet.

One can hear some echoes of noise music in the art games, but it has not yet been deeply rooted in the art games. The games by Jodi and some others have quasi-noise sound scores, but they are primitive compared to the rich variety of works 
produced in the noise music history since the 1950s. The art games by Jodi are made in a very ascetic manner on purpose, including their musical score. The acoustic and audio-visual findings in the field of noise are worth implementing in art games. Because the glitch effect, a twin of noise in the visual dimension, is now well established, one has to agree that the trend of noise used in the existing games is rather poor. Art Space intends to fill this gap in art games by showing the contemporary examples of noise music, its theoretical framework, its historical antecedents and a playful panel for creating noise-related sounds.

Taking into account that the acoustic aspect of music is its only true expression and that it cannot compete with linguistic description, this study only proposes a short outline of the art game scores and contemporary music examples to show that there is a large spectrum of sound possibilities that the creators of modern art gaming could use to enrich the design of games on acoustic level. Notwithstanding, this analysis is just an insight into the field and cannot represent the entire picture of the noise tradition due to the limits of a single article.

There is a category of games such as the Untitled Game (1996) by Jodi and Go Home Turtle Boy (2018) by Noah Abrigo that touches upon the glitch aesthetics in music. Jodi (Joan Heemskerk and Dirk Paesmans) and Abrigo use the sound of tape hiss, radio static, hum, scratching, squealing, crackling and other effects of digital glitch. Memory of a Broken Dimension (2015) by Ezra Hanson-White has a captivating spatial acoustic effect of dark ambient in a low register to metaphorically match the black and grey colors of the game's visual design. There are some recent gaming artworks with noise-related music scores that have merited the researcher's attention such as the VR crowd performance Emergence (2018) by Matt Pykes that demonstrates strident exclamations of a crowd and a massive vocal sound block. The virtual environment Ineffable Glossolalia (2017) by Tabitha Nikolai offers different virtual rooms with specific sound disturbances. Although the aforementioned art game works are interesting enough, one must conclude that they cannot compete with the diverse segment of noise-related acoustic possibilities that have been proposed in various fields of music.

Examples that qualify for the classical repertoire of noise music are the sounds of futuristic vehicles of Luigi Russolo (1885-1947) and the kinetic sculptures by Jean Tinguely (1925-1991). Although their means of technical production differ, the subtle acoustic impression of the kinetic sculptures is close to the Cartridge Music (1960) by John Cage. Cartridge Music is one of the most delicate noise music examples that demonstrates a soft buzzing, scratching of a magnetic tape, rattling, a kind of instrumental whispering and other surprising sounds. The chrestomatic 4'33" (1952) by John Cage is virtual noise music that presupposes some noise even in a silent concert hall. Studie 1 (1953) by Karlheinz Stockhausen is known as the first digital piece in the area of academic music. Despite its tingling, electronic sounds, this work has a soothing effect. Francesca Verunelli (b. 1979, Italy) and Katharina Rosenberger (b. 1971, Switzerland) are academic female composers who incorporate noise effects in their instrumental music in a sophisticated and sensible way. John Wiese (b. 1977, USA) has created extraordinary alternative music scores that incorporate sounds of creaking, soft bubbling, muffled clashing and other features of the untraditional acoustic world. It is gentle in comparison to the harsh electronic noise created by Masami Akita aka Merzbow (b. 1956, Japan), the wild rustling of the American noise band Sissy Spacek (USA) or the tameless noise project of Margaret Chardiet aka Pharmakon (b. 1990, USA) representing a mental state of trance characteristic to some underground social events of modern youth. This approach combined with a free improvisation and a quite aggressive noise is also a signature of the band Wolf Eyes (USA).

Luciano Berio's Sequenza III (1965) is an example of vocal noise-related music that presents an entire sound scale from shrilly, affective, noisy emotions mixed with a fine female singing voice. Poème Symphonique for 100 Metronomes (1962) by György Ligeti is a piece using the mechanical noise of metronomes reflecting the idea of Italian futurists. In academic music, other authors who have boldly developed the noise effect are Helmut Lachenmann (b. 1935, Germany), Michael Gordon (b. 1956, USA), and Mauro Lanza (b. 1975, Italy), to mention just a few. Sunshine of Your Love (1999) by Gordon is a piece for orchestra that produces a loud roaring sound that is unusual in the field of symphonic music.

In the area of alternative music, Richard Chartier (b. 1961, USA) follows the tradition of Cage's 4'33" by incorporating sounds into silence, including noises. Famous figures of noise are Alva Noto (or Carsten Nikolai, b. 1965) in Germany and Ryoji Ikeda (b. 1966, Japan, France) who creates audio-visual compositions with effects of a noise-related sound and visual glitch. Works by Ikeda are meditative ambient music enriched with noise effects. Original artists in the field were the quasimainstream indie pop group Oval (active at the end of 1980s and in the 1990s, Germany) and Bryn Jones (1961-1999, Great Britain) who worked under the name Muslimgauze. In Latvia, too, there are enjoyable noise music artists at the moment, like Jelena Glazova (b. in 1979) and the audio-visual collective Trihars.

\section{SituATION OF THE NOISE MUSIC DiscourSE}

The historical context of gaming aesthetics in general has been analyzed well enough using analysis of literature sources and examples of games. Gaming studies contain references to the historical styles and aesthetical theory of the games related to modernism, but mostly on an ideological level (audio-visual analysis is rare).

Celia Pearce touches upon the heritage from Fluxus and Dada and shows its importance in the conception of hacking in games [15]. Edwin Lohmeyer also admits the unquestionable reference in digital games to avant-garde concepts, notably Dadaism considering the playfulness and participatory aspect 
of games [16]. Mary Flanagan [17] shows the relation of Surrealism, Dada and Fluxus to gaming. Christiane Paul discusses the tendencies of modern gaming such as hypertextuality, random access and others using their historical background [18]. Abstractionism is a well-recognized category of games, and its relation to abstract art has been explained, for instance, by calling the abstract style in video games "an extension of abstract art" [19]. Aki Järvinen has classified the stylistic trends of games into three groups, photorealism, abstractionism and caricaturism [20], though without any direct reference to avant-garde of the first two. Bruno Samper has analyzed games in context of abstract art referring to the aesthetics of Wassily Kandinsky and Piet Mondrian [21]. There is a considerable number of monographs about digital art's tendencies in general but no comprehensive analysis of music in digital gaming. Recently, Cale Plut and Philippe Pasquier have published a survey of the current state of the art of generative music systems in games [22]. Yet a theoretical focus on noise music trend in gaming is absent. Karen Collins has carried out research into interaction of sound in gaming. She has touched upon the noise phenomenon too, although without any particular examination. Collins has mentioned a few games as examples of noisy sound scores such as Combat (1977) and Papa Sangre (2010), but the noise-related sound in particular has not been analyzed [23].

In the field of educational video games, contemporary arts in general have been scarcely represented, not to mention the sound aspect. A few games qualify for edugames concerning contemporary visual art, such as Patrick LeMieux' Art Games (2008-2009) and Prisme7 (2020). Video games have not been used before to teach contemporary aesthetics of sound, although there are games that teach various aspects of music such as Musichao (2007) and MELoDiA (2015) [24], [25]. There are also games outside the field of serious gaming where players can perform and even compose their own music like (LoTRO) (2007), Mabinogi (2004) or Glitch (2011).

In the literature of musicology, noise music and its cultural context have been well described. In 2002, Kim Cascone has declared that failure aesthetics including glitch, noise and other shifts from the traditional quality of sound, have become "prominent" [26]. Noise has been analyzed, including the subfields such as dark ambient, harsh noise wall, power electronics, noise pop, noise rock, psychedelic rock and others. In 2006, Doug van Nort has developed an overview of the noise trend taking into account industrial noise, found sound, application errors, glitches, randomness and others that constitute its wide scope. He states that in the last century the concept of noise has obtained numerous new and mutually differing meanings. It does not have, he writes, a single unambiguous meaning [27]. For this reason, the noise tradition merits a particular approach. It can be well done by means of modern media of gaming that can spark an interest of players and enlighten edgy ideas such as noise-related sound in an artistically sophisticated virtual environment. Thus, referring once again to Karen Collins, we could forge a new path "to explore and explain the many ways in which we play with sound" [23].

To conclude, there are very few games and works of game art that might qualify for the examples of noise tradition in the vast field of gaming. Also, in the theory of gaming the noiserelated sound has not been well documented. Art Space is a prototype of gaming that aims at filling this gap in digital edugames. Next to other aesthetical trends, Art Space incorporates the noise-related section that illustrates the manifestations of noise in contemporary gaming. The works of game art like Memory of a Broken Dimension, Untitled Game, Emergence and The Shrine Maidens of the Unseelie Court have been chosen as examples to represent the noise tradition in Art Game. The noise room invites the player to listen to the noise-related antecedents and contemporary witnesses such as Studie I by Stockhausen, works by Alva Noto, Oval, and others. Fig. 1 shows a screenshot from a game's demo version [28] with one of the historical antecedents of noise music, Cartridge Music by John Cage. Noise room is an intimately darkened hall with a chess-like floor and marble spheres where the user can wander and experiment with noise-related sounds as well as be informed about the cultural context of this phenomenon. In the Orbs of Knowledge, the user can read a textual information that sketches the theoretical ideas related to the concept of noise. This experimental game tends to enrich the field of serious gaming and answer specific musicological questions in a manner accessible to the general interest players.

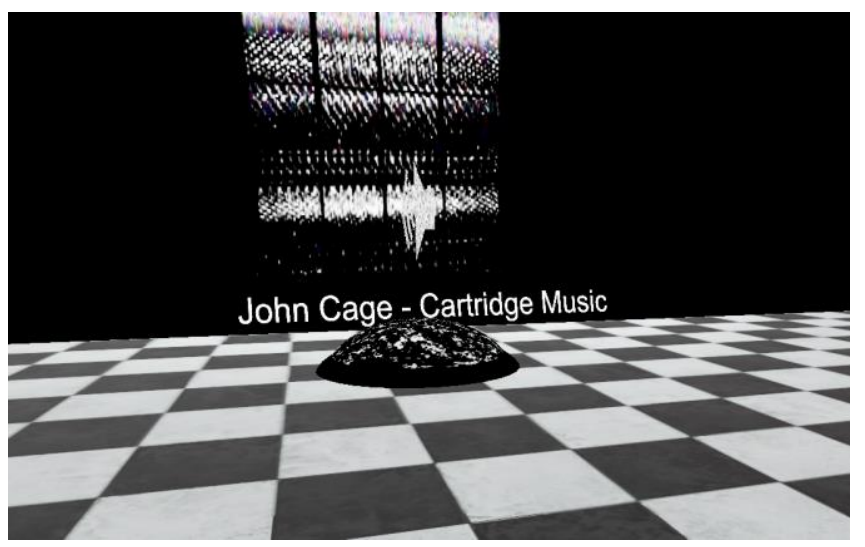

Fig. 1 Art Space. Noise room screenshot (Gintere, Biters, 2020) [28]

\section{CONCLUSION}

The goal of this research project is to facilitate the perception and comprehension of today's aesthetics by using the modern media of gaming. This paper is focused on the noise-related heritage of modernism in digital games. Art games show a great variety of stylistics inherited from modernism that recall the meaningful cultural backgrounds, shed light on contemporary thought in art and can help to write contemporary art's history. Yet the trend of noise has been utilized in games in a very limited way and its analysis in the theory of gaming is missing. The author of this study believes that the noise-related phenomena that nowadays do not imply 
negative connotations but rather belong to the contemporary ecosystem of sound, merit a specific attention and diverse exploitation in gaming.

\section{ACKNOWLEDGMENT}

I wish to express my sincere gratitude to Wayne Chislett for his support and proofreading as well as to Viestarts Gailītis, the founder of the festival Skaņu mežs (Sound Forest, Latvia) for the valuable information on the noise trend during the last years.

\section{References}

[1] I. Gintere, "A new digital art game: the art of the future" in $13^{\text {th }}$ International Scientific Conference "Society, Integration, Education" (SIE-2019) Proceedings, vol. 4, pp. 346-360. Rēzekne Academy of Technologies, $24^{\text {th }}-25^{\text {th }}$ May, 2019.

[2] I. Gintere, "Concept Music by Latvian Composers of the Youngest Generation", PhD thesis. Riga, Latvian Academy of Music, 2014, pp. 44-45.

[3] M. Flanagan, "Critical play: the productive paradox" in A Companion to Digital Art, C. Paul, Ed. Oxford: John Wiley, \& Sons, Inc., 2016, pp. 445-459.

[4] L. Russolo. The Art of Noises. New York, Great Bear Pamphlet, 1967 [1913], p. 5.

[5] J. Cage. Silence: Lectures and Writings by John Cage. Middletown, Wesleyan University Press, 1961, p. 3.

[6] L. Berio, Two Interviews/Luciano Berio. M. Boyars, New York, 1985.

[7] E. B. Hunter, "Building video game adaptations of dramatic and literary texts", in Research Methods for the Digital Humanities, L. Levenberg, T. Neilson, and D. Rheams, Eds. Cham: Palgrave Macmillan, 2018, pp. 173-194.

[8] U. Eco, The Role of the Reader: Explorations in the Semiotics of Texts. Indiana University Press, 1984.

[9] R. Barthes, "The death of the author" in Image-Music-Text. London: Fontana Press, 1977, pp. 142-148.

[10] M. Mortara, Ch. E. Catalano, F. Bellotti, G. Fiucci, M. HouryPanchetti, et al., "Learning cultural heritage by serious games" in Journal of Cultural Heritage, vol. XV (3), 2014, pp. 321-322.

[11] B. Bontchev, "Serious games for and as cultural heritage" in Digital Presentation and Preservation of Cultural and Scientific Heritage, vol. V. UNESCO, 2016, pp. 43-58.

[12] E. F. Anderson, L. McLoughlin, F. Liarokapis, Ch. Peters, P. Petridis, et al., "Developing serious games for cultural heritage: a state-of-the-art Review" in VAST 2009: $10^{\text {th }}$ International Symposium on Virtual Reality, Archaeology and Cultural Heritage, Valletta, 2009, pp. 29-48.

[13] D. Ferdani, B. Fanini, M. C. Piccioli, F. Carboni, P. Vigliarolo, "3D reconstruction and validation of historical background for immersive VR applications and games: the case study of the forum of Augustus in Rome" in Journal of Cultural Heritage, vol. 43, 2020, pp. 129-143.

[14] G. Baptista, T. Oliveira, "Gamification and serious games: a literature meta-analysis and integrative model" in Computers in Human Behavior, 92, 2019, pp. 306-315.

[15] C. Pearce, "The aesthetics of play" in Visible Language, XL (1). California: Rhode Island School of Design, 2006, pp. 6689.
[16] E. Lohmeyer, "Please do touch (and disrupt) in art: glitchkinesthetics and spectator agency in Super Metroid: Nightmare Edition" in Video Game Art Gallery, July 03, 2018.

[17] M. Flanagan, Critical Play: Radical Game Design. Cambridge etc.: The MIT Press, 2009.

[18] C. Paul, Digital Art. London: Thames \& Hudson, 2003.

[19] M. J. P. Wolf, "Abstraction in the video game" in The Video Game Theory Reader, M. J. P. Wolf and B. Perron, Eds. New York, London: Routledge, 2003, pp. 47-57.

[20] A. Järvinen, "Gran stylissimo: the audiovisual elements and styles in computer and video games", in Proceedings of Computer Games and Digital Cultures Conference, F. Mäyrä, Ed. Tampere: Tampere University Press, 2002, pp. 113-128.

[21] B. Samper, "Les artistes et le jeu video" in Leonardo/Olats, March, Paris, 2003. Available at: http://www.olats.org/projetpart/artmedia/2002/t_bSamper.html.

[22] C. Plut, P. Pasquier, "Generative music in video games: state of the art, challenges, and prospects", in Entertainment Computing 33, 2020, 100337, pp. 1-19.

[23] K. Collins, Playing with Sound: A Theory of Interacting with Sound and Music in Video Games. Cambridge: The MIT Press, 2013.

[24] R. Chao-Fernandez, S. Román-García, A. Chao-Fernandez, "Analysis of the use of ICT through music interactive games as educational strategy", 7th International Conference on Intercultural Education "Education, Health and ICT for a Transcultural World", EDUHEM 2016, 15-17 June, Almeria, Spain. In Procedia - Social and Behavioral Sciences, 237, 2017, pp. 576-580.

[25] M. Nouwen, S. Schepers, K. Mouws, K. Slegers, N. Kosten, P. Duysburgh, "Designing an educational music game: what if children were calling the tune?" in International Journal of Child-Computer Interaction, vol. 9-10, 2016, pp. 20-32.

[26] D. van Nort, "Noise/music and representation systems" in Organized Sound, vol. XI (02). Cambridge University Press, 2006, DOI: 10.1017/S1355771806001452, pp. 173-178.

[27] K. Cascone, "The aesthetics of failure: "post-digital" tendencies in contemporary computer music" in Computer Music Journal, vol. XXIV (4). Cambridge: MIT Press, 2002, pp. 12-18.

[28] I. Gintere, K. Biters, Art Space, a demo version, 2020. Available at: http://artspace.va.lv.

\section{Sources of funding for research presented in the article}

Supported by the European Regional Development Fund, project No. 1.1.1.2/VIAA/1/16/106 within the Activity 1.1.1.2 "Post-doctoral Research Aid".

\section{Creative Commons Attribution License 4.0 (Attribution 4.0 International, CC BY 4.0)}

This article is published under the terms of the Creative Commons Attribution License 4.0

https://creativecommons.org/licenses/by/4.0/deed.en_US 